\title{
Prolonged Preterm Rupture of Fetal Membranes, a Consequence of an Increased Maternal Anti-fetal T Cell Responsiveness
}

\author{
ANDREA STEINBORN, EDGAR SCHMITT, YVONNE STEIN, ANDREAS KLEE, \\ MARKUS GONSER, ERHARD SEIFRIED, AND CHRISTIAN SEIDL
}

\begin{abstract}
Department of Obstetrics and Gynecology [A.S., Y.S.], University of Frankfurt, 60590 Frankfurt/Main, Germany; Institute of Immunology [E.Sc.], University of Mainz, 55131 Mainz, Germany; Department of Obstetrics and Gynecology [A.K., M.G.], Dr. Horst-Schmidt Hospital, 65199 Wiesbaden, Germany; and Institute of Transfusion Medicine and Immunohaematology [E.Se., C.S.], Blood Transfusion Center of the German Red Cross, 60528 Frankfurt, Germany
\end{abstract}

\begin{tabular}{|c|c|}
\hline \multicolumn{2}{|c|}{ ABSTRACT } \\
\hline $\begin{array}{l}\text { A fetus, although semi-allogeneic, is usually accepted by the } \\
\text { maternal immune system. However, complications, including } \\
\text { alloresponsive mechanisms, are thought to be potentially detri- } \\
\text { mental for a successful pregnancy. Therefore, we compared } \\
\text { allogeneic T cell responses of nonpregnant women with the } \\
\text { response of healthy pregnant women and pregnant women who } \\
\text { have various gestation-associated diseases. Peripheral blood } \\
\text { mononuclear cells (PBMCs) of all three groups were stimulated } \\
\text { with PBMCs from unrelated volunteers. Pregnant women had } \\
\text { significantly reduced stimulation indices (SIs) compared with } \\
\text { nonpregnant women. Exposing PBMCs from pregnant women to } \\
\text { PBMCs of their own fetus led to a further significant decrease of } \\
\text { SIs. Among the two groups of pregnant individuals, SIs of } \\
\text { women with prolonged preterm rupture of fetal membranes } \\
\text { (PPROM) were significantly higher when the maternal PBMCs } \\
\text { were stimulated with PBMCs of their own fetus. This phenom- } \\
\text { enon could not be observed after stimulation with PBMCs from } \\
\text { unrelated volunteers. In addition, an increased humoral immune } \\
\text { response was assessed for women with PPROM in comparison }\end{array}$ & $\begin{array}{l}\text { with women with uncontrollable preterm labor. Our results re- } \\
\text { vealed a strongly reduced allogeneic T cell response of PBMCs } \\
\text { from pregnant women that was further down-regulated when } \\
\text { PBMCs from their own fetus were used as stimulators. By } \\
\text { contrast, data from women with PPROM suggest an increased } \\
\text { maternal T cell response specifically toward the fetal HLA } \\
\text { antigens.(Pediatr Res 58: 648-653, 2005) } \\
\qquad \text { Abbreviations } \\
\text { CTG, cardiotocogram } \\
\text { HELLP, hemolysis, elevated liver enzymes, low platelet count } \\
\text { IUGR, intrauterine growth restriction } \\
\text { MLC, mixed lymphocyte culture } \\
\text { MMP, matrix metalloprotease } \\
\text { PBMC, peripheral blood mononuclear cells } \\
\text { PL, preterm labor } \\
\text { PPROM, prolonged preterm rupture of fetal membranes } \\
\text { SI, stimulation index } \\
\text { TNF, tumor necrosis factor }\end{array}$ \\
\hline
\end{tabular}

During pregnancy the maternal immune system is confronted with paternal allo-antigens expressed by the fetal tissues. Therefore, maternal immune rejection processes toward fetal HLA antigens may represent a major cause of complications, such as uncontrollable preterm labor (PL), prolonged preterm rupture of fetal membranes (PPROM), pregnancyinduced hypertensive diseases [preeclampsia; hemolysis, elevated liver enzymes, low platelets (HELLP) syndrome] or intrauterine growth restriction (IUGR). Several local mecha-

Received November 17, 2004; accepted February 11, 2005

Correspondence: Andrea Steinborn, Ph.D., Department of Obstetrics and Gynecology, University of Heidelberg Voßtrasse 9, 69115 Heidelberg, Germany; e-mail: andrea.steinborn@med.uni-heidelberg.de.

DOI: 10.1203/01.PDR.0000180541.03425.76 nisms that act at the maternal-fetal interface to protect the fetus from maternal immune attack are known (1). In addition, mechanisms that induce peripheral immune tolerance to the fetus seem to be of equal if not of greater importance for successful course of pregnancy.

One such mechanism is most possibly the induction of $\mathrm{CD} 25+\mathrm{CD} 4+\mathrm{T}$ regulatory cells, a specialized $\mathrm{T}$ cell population that was shown not only to suppress autoaggressive immune responses (2) but also to prevent graft rejection as a result of induction of transplantation tolerance (3). Pregnancyinduced expansion of these regulatory $\mathrm{T}$ cells occurs in both mice (4) and humans (5). These cells were able to suppress the allogeneic $\mathrm{T}$ cell response directed against the fetus (4). Recently, it was reported that normal human pregnancy also is 
associated with an increased number of regulatory $\mathrm{T}$ cells in the maternal circulation (5).

Other mediators that influence peripheral immune tolerance are soluble HLA (sHLA) class I molecules. Soluble forms of HLA-A, -B, -C, and -G were shown to inhibit cytotoxic T cell activity through CD8 ligation, leading to increased apoptosis by Fas/Fas-ligand interaction of these cells $(6-8)$. Thus, increased availability of sHLA class I molecules may have strong immune-suppressive effects and affect potentially maternal immune homeostasis. Besides these nonspecific effects on the immune response, sHLA class I molecules have specific effects on the allogeneic $\mathrm{T}$ cell response. These molecules induce the apoptosis of cytotoxic $\mathrm{T}$ lymphocytes through binding to their corresponding $\mathrm{T}$ cell receptors $(9-11)$. Therefore, maternal alloreactive $\mathrm{T}$ cells could be blocked by fetally derived sHLA class I molecules. By this way, the maternal $\mathrm{T}$ cell response directed specifically against the fetal HLA class I antigens is suppressed, whereas the $\mathrm{T}$ cell response against other unrelated allogeneic donors is not influenced.

We show here that the alloreactive immune response toward peripheral blood mononuclear cells (PBMCs) from healthy adults was considerably reduced in pregnant compared with nonpregnant women. This alleviated response was further strongly diminished when PBMCs that were isolated from the individual fetus were the targets. The same finding could be observed in pregnant women who experience various gestation-associated diseases. An exception were women who had PPROM and exhibited a comparatively high alloresponse, suggesting an increased anti-fetal reaction under these conditions.

\section{METHODS}

Participants in the mixed lymphocyte culture reaction study. This study was approved by the Regional Ethics Committee. Informed consent was obtained from all participants. From June 2002 until February 2003, EDTA plasma samples were collected from 96 healthy male or female volunteers, who constituted the nonpregnant control group, and from 137 pregnant women in the third trimester. All pregnant women were classified into five different groups according to pregnancy complications and outcome. From these pregnant women, both maternal and cord blood samples were consecutively collected immediately after delivery. Clinical characteristics of all of these patients are detailed below and summarized in Table 1. As sufficient volumes of both maternal and fetal blood samples were necessary for the mixed lymphocyte culture (MLC) reaction studies, a period of 9 mo was needed to get at least 10 patients per group. This study represents an explorative pilot study for which no previous knowledge exists. All experiments were done for the first time. Therefore, we were not able to do a sample size calculation to calculate the expected number of patients that would be necessary to test for the assessment of significant differences between groups. We finished our study after having recruited at least 10 patients per group and checked our results for significant differences of the patient groups as described below.

Group 1 consisted of 68 healthy women who delivered term neonates (38-42 wk gestation) with normal birth weight, after the onset of spontaneous term labor $(n=42)$ or elective cesarean section because of cephalopelvic disproportion, breech presentation, repeated cesarean section, or fear of vaginal birth $(n=26)$. Group 2 consisted of 15 women who delivered preterm (25-37 wk gestation) because of uncontrollable PL associated with progressive dilation of the os uteri or fetal heart rate patterns necessitating immediate delivery [pathologic cardiotocogram (CTG)]. For all of these women, rupture of fetal membranes occurred after the onset of labor, and latency from membrane rupture to delivery was $<24 \mathrm{~h}$ in all cases. Depending on gestational age and clinical symptoms, pregnancy was interrupted by cesarean section $(n=7)$ or spontaneous delivery $(n=8)$.

Group 3 consisted of 20 women who delivered preterm (25-37 wk gestation) with diagnosis of PPROM. This diagnosis was defined as spontaneous membrane rupture that occurred before the onset of labor. For all women in this group, rupture of fetal membranes occurred at least $24 \mathrm{~h}$ before the onset of labor. Five of these women received labor-promoting drugs because fetal lung maturity was attained. Six patients delivered by cesarean section, and 14 women delivered spontaneously after the onset of labor.

Table 1. Clinical characteristics and stimulation index (SI) of patients participating in the mixed lymphocyte culture (MLC) reaction study

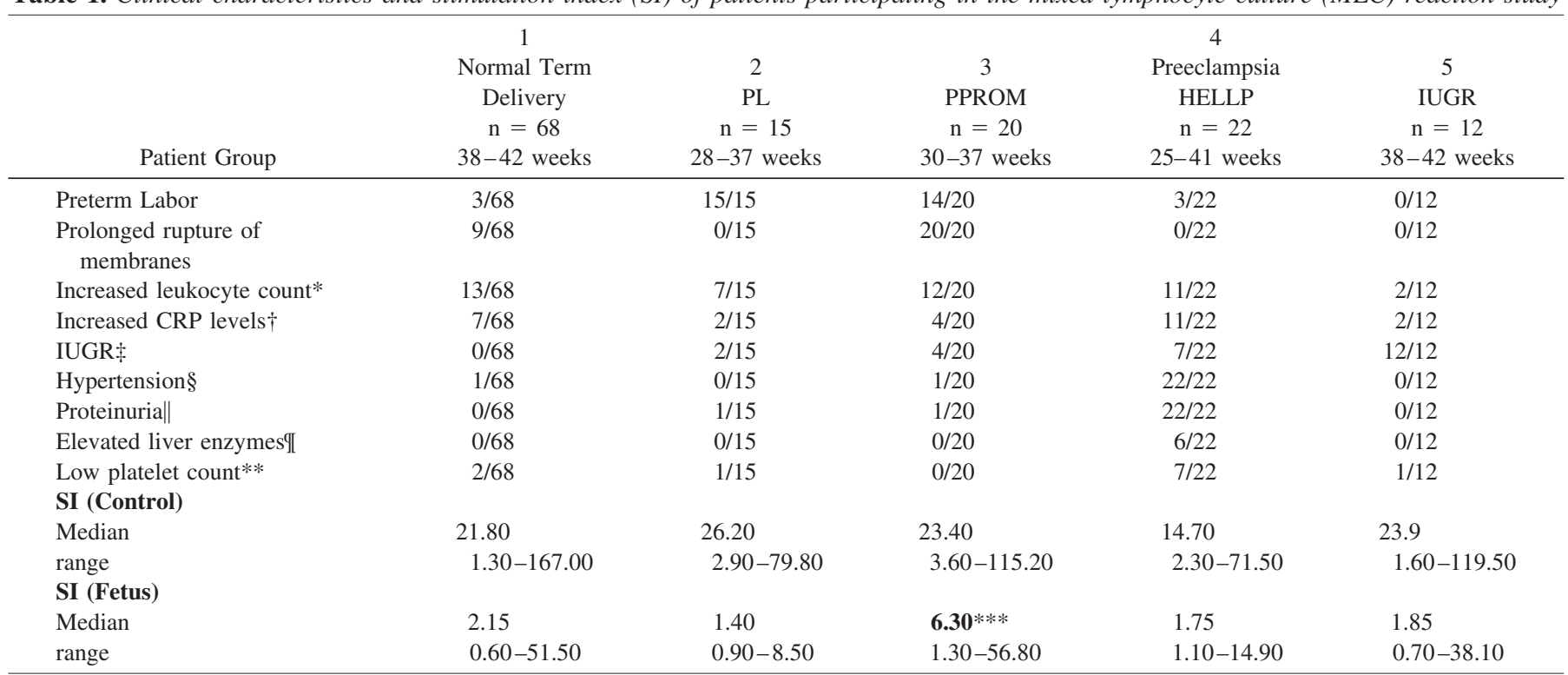

$\mathrm{PL}=$ Preterm Labor; PPROM $=$ Prolonged preterm rupture of fetal membranes; IUGR $=$ Intrauterine growth retardation; HELLP $=$ Hemolysis, Elevated Liver enzymes, Low Platelet count; * (leukocytes $>11.500 / \mu \mathrm{l}) ; \dagger(\mathrm{C}$-reactive protein levels $>1 \mathrm{mg} / \mathrm{dl}$ ), $\ddagger$ (birth weight $<10$ th percentile for gestational age), $\S$ (blood pressure $>140 / 90 \mathrm{~mm} \mathrm{Hg}$ in two determinations apart), $\|(>300 \mathrm{mg}$ per $24 \mathrm{~h})$; I ( aspartate aminotransferase and alanine aminotransferase $>30 \mathrm{U} / \mathrm{I})$, ** (thrombocyte count $<150.000 / \mu 1$ ); *** Statistical differences were detected between PPROM and Normal Term delivery $(\mathrm{p}<0.05$ ), between PPROM and Preterm labor $(\mathrm{p}<0.005)$, between PPROM and preeclampsia/HELLP $(\mathrm{p}<0.05)$ and between PPROM and IUGR $(\mathrm{p}<0.05)$. 
Group 4 consisted of 22 patients (25-41 wk gestation) with clinical symptoms of preeclampsia $(n=16)$ or HELLP syndrome $(n=6)$. Preeclampsia was diagnosed in the presence of a blood pressure of $>140 / 90 \mathrm{~mm} \mathrm{Hg}$ at two separate occasions, $6 \mathrm{~h}$ apart, along with significant proteinuria $(>300$ $\mathrm{mg} / \mathrm{L}$ in a $24-\mathrm{h}$ collection or a dipstick reading of $>2+$ on a voided random urine sample in the absence of urinary tract infection) in previously normotensive women. In seven cases, hypertension was complicated by IUGR. The diagnosis of HELLP-syndrome was made when hemolysis, elevated liver enzyme levels, and thrombocytopenia were present. The laboratory parameters of these patients were serum haptoglobin concentrations $<0.3 \mathrm{~g} / \mathrm{L}$, thrombocyte count $<150,000$ cells $/ \mu \mathrm{L}$, and aspartate aminotransferase and alanine aminotransferase $>30 \mathrm{U} / \mathrm{L}$. All of these patients showed characteristic clinical symptoms such as left-sided epigastric pain, flickering in front of one's eyes, and exaggerated reflexes. In this group, eight patients delivered spontaneously after administration of labor-promoting drugs, and 14 women had a cesarean section because of fetal or maternal indication.

Group 5 consisted of 12 patients at term (38-42 wk gestation) who delivered by cesarean section $(n=4)$ or vaginally after induction of labor because of a growth-restricted fetus $(n=8)$. Labor was induced in case of ultrasonographic detection of fetal growth arrest and advanced gestational age. Cesarean section was done in case of pathologic fetal Doppler findings or fetal heart rate patterns necessitating cesarean delivery (pathologic CTG). After delivery, IUGR was diagnosed in case of a birth weight $<10$ th percentile for gestational age. None of the fetal growth-restricted cases was complicated by preeclampsia or HELLP syndrome.

Participants in the anti-HLA antibody detection study. The experimental design of the initial MLC reaction study did not include the collection of serum samples. Hence, as we realized that the occurrence of PPROM was associated with an increased alloreactive $\mathrm{T}$ cell response of the mother against the fetal HLA antigens, we could not check for anti-HLA antibodies because no serum samples had been stored. Consequently, we recruited a new collective of women with PPROM and a second with uncontrollable PL for comparative analysis of anti-HLA antibodies. This study was also approved by the Regional Ethics Committee, and informed consent was obtained from all participants. The serum samples were collected consecutively from March 2003 until August 2003. The clinical characteristics of these 83 women, stratified into two different groups, are detailed below and summarized in Table 2. As this study also represents an explorative pilot study, it was not possible to calculate the expected number of patients to be tested to demonstrate significant differences between groups. Samples were collected until at least 30 patients per group were recruited. Results were checked for significant differences between the patient groups as described below.

Group A consisted of 46 women who delivered preterm (25-37 wk gestation) because of uncontrollable PL associated with cervical insufficiency or pathologic CTG necessitating immediate delivery. For all of these women,

Table 2. Clinical characteristics of patients participating in the anti-HLA-antibody detection study

\begin{tabular}{|c|c|c|}
\hline Patient Group & $\begin{array}{c}\mathrm{A} \\
\mathrm{PL} \\
\mathrm{n}=46 \\
25-37 \text { weeks }\end{array}$ & $\begin{array}{c}\text { B } \\
\text { PPROM } \\
\mathrm{n}=37 \\
25-37 \text { weeks }\end{array}$ \\
\hline Preterm Labor & $46 / 46$ & $32 / 37$ \\
\hline $\begin{array}{l}\text { Prolonged rupture of } \\
\text { membranes }\end{array}$ & $0 / 46$ & $37 / 37$ \\
\hline Increased leukocyte count* & $8 / 46$ & $13 / 37$ \\
\hline Increased CRP levels $\dagger$ & $12 / 46$ & $12 / 37$ \\
\hline IUGR & $2 / 46$ & $3 / 37$ \\
\hline Hypertension§ & $2 / 46$ & $1 / 37$ \\
\hline Proteinuria $\|$ & $0 / 46$ & $1 / 37$ \\
\hline Elevated liver enzymesđI & $3 / 46$ & $0 / 37$ \\
\hline Low platelet count** & $0 / 46$ & $0 / 37$ \\
\hline $\begin{array}{l}\text { anti-HLA-positive patients } \\
\text { number }(\%)\end{array}$ & $7 / 46(15.2 \%)$ & $15 / 37(40.5 \%)^{* * *}$ \\
\hline
\end{tabular}

$\mathrm{PL}=$ Preterm Labor; PPROM $=$ Prolonged preterm rupture of fetal membranes; IUGR $=$ Intrauterine growth retardation; $*$ (leukocytes $>11.500 /$ $\mu \mathrm{l}$ ), $\dagger($ C-reactive protein levels $>1 \mathrm{mg} / \mathrm{dl}$ ), $\ddagger$ (birth weight $<10$ th percentile for gestational age), $\S$ (blood pressure $>140 / 90 \mathrm{~mm} \mathrm{Hg}$ in two determinations apart), $\|(>300 \mathrm{mg}$ per $24 \mathrm{~h})$, II (aspartate aminotransferase and alanine aminotransferase $>30 \mathrm{U} / \mathrm{I}$ ), $* *$ (thrombocyte count $<150.000 / \mu \mathrm{l}$ ); *** Statistical differences were detected between PPROM and Uncontrollable Preterm Labor $(\mathrm{p}<0.05)$. rupture of fetal membranes occurred after the onset of labor, and latency from membrane rupture to delivery was $<24 \mathrm{~h}$ in all cases. Depending on gestational age and clinical symptoms, pregnancy was interrupted by cesarean section $(n=28)$ or spontaneous delivery $(n=18)$.

Group B consisted of 37 women who delivered preterm ( $<37$ wk gestation) with a diagnosis of PPROM. For all of these women, rupture of fetal membranes occurred at least $24 \mathrm{~h}$ before the onset of labor. In this group, five women received labor-promoting drugs because fetal lung maturity was attained. Nineteen patients delivered by cesarean section, and 14 women delivered spontaneously after the onset of labor.

MLC reaction. Anticoagulated blood samples were collected from 96 nonpregnant healthy volunteers and from 137 pregnant women stratified into five different groups as described above. PBMCs were isolated by FicollHypaque density gradient centrifugation. For MLC reactions of nonpregnant individuals, $1 \times 10^{5}$ mononuclear cells from each individual served as responder cells and were stimulated with $1 \times 10^{5}$ pooled cells from at least three different, unrelated volunteers. MLC reactions were also done with cells from pregnant women. For these experiments, $1 \times 10^{5}$ mononuclear cells from each pregnant woman served as responder cells and were stimulated with $1 \times$ $10^{5}$ mononuclear cells of their own fetus or with $1 \times 10^{5}$ pooled cells from at least three unrelated volunteers. All different series of MLC reactions were performed according to the scheme shown in Table 3.

In all experiments, cells were incubated in $240 \mu \mathrm{L}$ of RPMI culture medium supplemented with $10 \%$ FCS for $5 \mathrm{~d}$. Stimulating cells were irradiated with 25 Gy before incubation. Autologous controls were done, preparing cultures that contained stimulating and responding cells from the same individual. Cultured cells were labeled with ${ }^{3} \mathrm{H}$-thymidine $(1 \mu \mathrm{Ci} /$ well $)$ incorporation for an additional culture period of $18 \mathrm{~h}$ after which the cells were harvested. The amount of ${ }^{3} \mathrm{H}$-thymidine incorporation was measured by liquid scintillation counting. Results expressed as stimulation index (SI) were calculated as a ratio between the count per minute (cpm) obtained in the allogeneic combination, divided by the cpm obtained in the appropriate autologous control.

Determination of anti-HLA class I and II specific antibodies. Anti-HLA class I and II antibodies were detected in serum samples that were obtained from women who delivered preterm and were stratified in two different groups (PL $n=46$; PPROM $n=37$ ). Blood samples were taken at admission into the delivery room, normally within $24 \mathrm{~h}$ before delivery, and centrifuged at $1500 \times g$ for $10 \mathrm{~min}$ at $4{ }^{\circ} \mathrm{C}$. The serum was removed and stored in aliquots at $-80^{\circ} \mathrm{C}$ until assayed. Antibody (IgG) detection was performed using "LAMBDA ANTIGEN TRAY" qualitative ELISA kits (One Lambda, Inc., Canoga Park, CA) according to the manufacturer's instructions. Subsequently, the data were analyzed using One Lambda proprietary software (LAT-LCT Software). LAT-LCT is a computer program that was designed to efficiently retrieve and analyze the results of the LAMBDA ANTIGEN TRAY assay. This panel reactive antibody testing allows the qualitative detection of anti-HLA class I and class II IgG antibodies in the maternal circulation. In most cases, interpretation of the results also allows the definition of antibody specificity.

Statistical analysis. Statistical comparison of SI values among the different patient populations was done using the nonparametric Wilcoxon-MannWhitney $U$ test. $p<0.05$ was considered significant. Statistical evaluation of the presence of anti-HLA antibodies in the maternal circulation of the different patient populations was done using Fisher's exact test. $p<0.05$ was considered significant.

Table 3. Preparation scheme for mixed lymphocyte culture (MLC) reactions

\begin{tabular}{lcc}
\hline & \multicolumn{2}{c}{ Stimulator } \\
\cline { 2 - 3 } Responder & Pool* $^{*}$ & Fetus $\dagger$ \\
\hline Non-pregnant Volunteers & $\mathrm{X}$ & - \\
Women with normal pregnancies (group 1) & $\mathrm{X}$ & $\mathrm{X}$ \\
Women with complicated pregnancies: & & \\
PL (group 2) & $\mathrm{X}$ & $\mathrm{X}$ \\
PPROM (group 3) & $\mathrm{X}$ & $\mathrm{X}$ \\
Preeclampsia/HELLP-Syndrome (group 4) & $\mathrm{X}$ & $\mathrm{X}$ \\
IUGR (group 5) & $\mathrm{X}$ & $\mathrm{X}$ \\
\hline
\end{tabular}

* Peripheral blood mononuclear cells (PBMCs) were taken from at least three different healthy volunteers and used as mixed cell pool.

$\dagger$ Maternal PBMCs were stimulated with PBMCs of their own fetus.

$\mathrm{PL}=$ Preterm Labor; PPROM = Prolonged rupture of fetal membranes; HELLP = Hemolysis, Elevated Liver enzymes, Low Platelets; IUGR = Intrauterine Growth Restriction. 


\section{RESULTS}

The allogeneic $T$ cell response of pregnant women is significantly decreased in comparison with nonpregnant women. MLC reactions of PBMCs from 96 healthy, nonpregnant volunteers toward pooled cells from at least three different, unrelated volunteers were done to examine the allogeneic $\mathrm{T}$ cell reactivity of a normal control group. The SIs obtained for each of these individuals are shown in Fig. 1A. MLC reactions were also performed with 68 healthy pregnant women at term. The maternal PBMCs were stimulated with pooled cells from at least three different, unrelated volunteers (Fig. $1 B$ ) or with PBMCs of their own fetus (Fig. 1C). We found significantly decreased SIs for the group of healthy pregnant women (median value 21.80; range $1.30-167.00$ ) in comparison with the nonpregnant individuals of the control group (median value 62.53; range 8.44-379.49). There was a further strong decrease of SIs when the maternal PBMCs were stimulated with PBMCs of their own fetus (median value 2.15; range 0.60-51.50) instead of PBMCs from unrelated volunteers. These findings suggest that the cellular immune response in pregnant women is strongly diminished, especially in response to their semi-allogeneic fetus.

PPROM is associated with an increased maternal T cell response against the semi-allogeneic fetus. MLC reactions were also done with PBMCs from 69 pregnant women with various gestation-associated diseases. The maternal PBMCs were stimulated with pooled cells from healthy, unrelated volunteers and with cells of their own fetus. The clinical characteristics and SIs (median and range) of these patients, stratified into five different groups, are summarized in Table 1. We observed a significant proliferative response of the maternal $\mathrm{T}$ cells from both normal term and affected women toward allogeneic control cells (Fig. $2 A$ and Table 1). By contrast, this proliferative response was strongly depressed when the maternal cells were stimulated with the PBMCs of their own semiallogeneic fetus (Fig. $2 B$ and Table 1). We did not detect any significant differences of SIs between the patients in these five

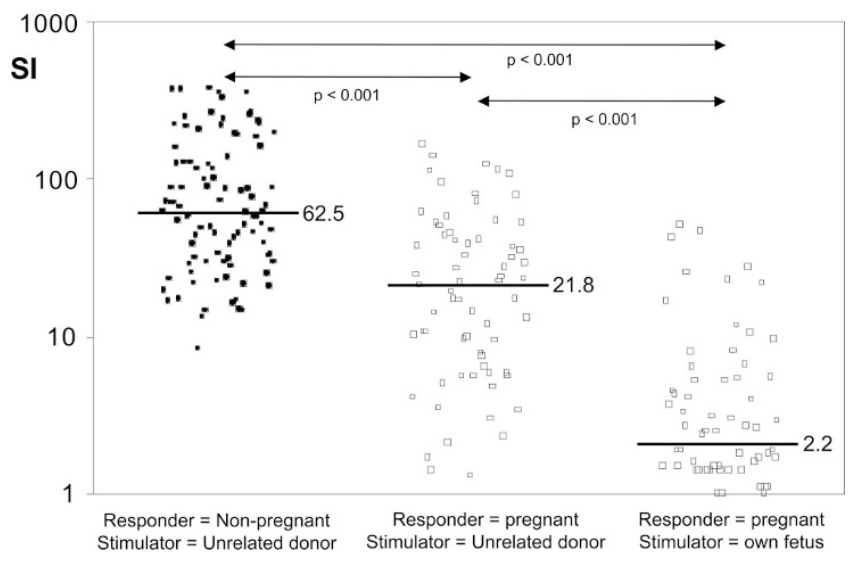

Figure 1. Low MLC responses of healthy, pregnant individuals against unrelated adult PBMCs are strongly reduced when PBMCs from their own fetus are used as stimulators. SIs of 96 healthy, nonpregnant individuals (-) and 68 healthy, pregnant women at term $(\bigcirc)$ are shown. T cells of nonpregnant individuals were stimulated with pooled cells that were obtained from unrelated donors $(A)$. T cells of pregnant term women were stimulated with cells that were obtained from unrelated donors $(B)$ or with cells that were obtained from their own fetus $(C)$.

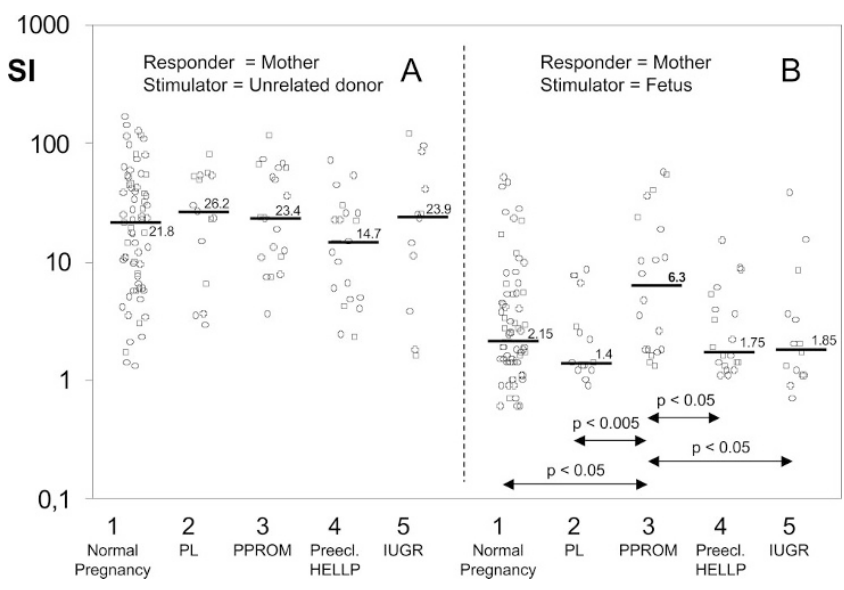

Figure 2. Pregnant individuals who experience PPROM exhibit an increased MLC response to PBMCs from their own fetus. SIs of 68 healthy, pregnant women at term (group 1), 15 women who delivered preterm because of uncontrollable labor (group 2), 20 women who delivered preterm because of PPROM (group 3), 22 women with preeclampsia or HELLP syndrome (group 4), and 12 women with IUGR (group 5) are shown. The maternal T cells were stimulated with pooled cells of unrelated donors $(A)$ or stimulated with cells of their own fetus $(B)$.

groups when the maternal $\mathrm{T}$ cells were stimulated with pooled cells from unrelated volunteers (Fig. $2 A$ and Table 1). Surprising, we detected significant differences between these patient groups when the maternal PBMCs were stimulated with cells of their own semi-allogeneic fetus (Fig. $2 B$ and Table 1). Namely, we found significantly increased SIs for patients with PPROM (median SI 6.30; range 1.30-56.80) in comparison with women with normal term delivery (median SI 2.15; range $0.60-51.50 ; p<0.05)$ but also in comparison with patients with other pregnancy-associated diseases such as preeclampsia/HELLP syndrome (median SI 1.75; range 1.10-14.90; $p<$ 0.05 ) and IUGR (median SI 1.85; range 0.70-38.10; $p<0.05$ ). The most strengthened differences were detected between patients with PPROM and patients with uncontrollable PL (median SI 1.40; range $0.90-8.50 ; p<0.005$ ). There were no significant differences among women with normal term labor (median SI 2.25; range $0.60-42.9 ; n=42$ ), patients with uncontrollable preterm labor, and patients with term elective cesarean section in the absence of labor (median SI 2.15; range $0.70-51.5 ; n=26$; data not shown). These results show that the status of labor obviously does not have an effect on the proliferative response of the maternal $\mathrm{T}$ cells.

PPROM is associated with an increased detection of antiHLA antibodies in the maternal circulation. Our MLC studies clearly demonstrated an increased cellular anti-fetal immune response for women with PPROM compared with women with uncontrollable PL. Therefore, we examined whether an increased humoral immune response toward the fetal HLA antigens could also be detected for women with PPROM in comparison with women with PL. In a consecutive study, the formation of anti-HLA antibodies was tested in plasma samples that were collected from 46 women who delivered preterm because of uncontrollable PL (25-37 wk gestation) and 37 women who delivered preterm with diagnosis of PPROM (25-37 wk gestation). Clinical data of the patients in these two 
groups are summarized in Table 2. The presence of antibodies directed against HLA antigens was performed using One Lambda-ELISA kits in combination with LAT-LCT Software as described before. The presence of anti-HLA antibodies was detected for seven patients with uncontrollable PL (15.2\%) and for 15 patients with PPROM (40.5\%). Statistical evaluation revealed that the number of individuals who generated antiHLA antibodies was significantly $(p<0.05)$ increased in the group of patients with PPROM in comparison with women with uncontrollable PL (Table 2).

\section{DISCUSSION}

Pregnancy can be considered as a successful transplantation of allogeneic paternal tissues to the mother. In the present study, we preferentially used the MLC reaction to analyze a potential maternal anti-fetal immune response. We found that the proliferative $\mathrm{T}$ cell response after allogeneic stimulation was significantly decreased in pregnant women in comparison with a nonpregnant control group. As regulatory $\mathrm{T}$ cells were shown to reduce the allogeneic $\mathrm{T}$ cell response after organ transplantation $(12,13)$, it seems that this effect may be mediated by the expansion of these cells during pregnancy. We also found that there was a further significant decrease of the maternal allogeneic $\mathrm{T}$ cell response when the cells were stimulated with PBMCs cells of their own fetus, instead of cells from unrelated volunteers. These findings suggest that additional mechanisms that suppress the maternal $\mathrm{T}$ cell response specifically toward the allo-antigens of the fetus may exist. In pregnancy, this suppressive effect may be achieved by the interaction of fetally derived soluble HLA class I antigens with the $\mathrm{T}$ cell receptors of the corresponding maternal cytotoxic $\mathrm{T}$ cells. Alloreactive cytotoxic T cells persist in the mother and may cause fetal rejection if deficient amounts of soluble HLA class I molecules reach the maternal circulation. For organ transplantation, it was already demonstrated that increased detection of donor-derived soluble HLA class I molecules was associated with prolongation of graft survival and induction of tolerance (14). Therefore, it seems that maternal immune tolerance toward the fetal allo-antigens may be achieved by different mechanisms involving both the induction of regulatory $\mathrm{T}$ cells and the release of soluble fetal HLA class I molecules into the maternal circulation.

With regard to different pregnancy-associated diseases, we could not detect significant differences of SIs after allogeneic stimulation between women with normal term delivery and women with various pregnancy complications. In contrast, the occurrence of PPROM was definitely found to be characterized by an increased maternal $\mathrm{T}$ cell response when the maternal cells were stimulated with cells of their own fetus. SIs of women with PPROM were significantly increased in comparison with women with normal term delivery and also in comparison with women with other complications in pregnancy. These findings support the idea that maternal $\mathrm{T}$ cell reactions specifically directed toward the fetal allo-antigens may be involved in the pathogenesis of PPROM. As an increased humoral anti-fetal immune response was also detected for women with PPROM, it seems that both cytotoxic T cells and T-helper cells may react in case of PPROM. Our study is the first one to show that the occurrence of PPROM is associated with an increased maternal $\mathrm{T}$ cell reactivity toward the fetal allo-antigens. Because of small patient numbers in each group, our experience in this field is still small. Further studies will be necessary to confirm our findings concerning the importance of peripheral tolerance induction for pregnancyspecific complications such as PPROM. At present, we cannot state definitively that an inadequate release of highly polymorphic HLA class I molecules from fetal tissues may principally be involved in the pathogenesis of PPROM. For normal pregnancy, it is known that a significant elevation of soluble HLA class I blood levels occurs in the first two trimesters, which drops below normal levels at the end of pregnancy (15). As well, we cannot rule out that soluble forms of the relatively nonpolymorphic HLA-G molecules may additionally contribute to insufficient apoptosis of alloreactive cytotoxic T cells in pregnancy. Decreased levels of soluble HLA-G were already detected in the presence of placental abruption (16) and preeclampsia (17).

In the literature, little information exists about the precise pathophysiology of PPROM, which affects $\sim 3 \%$ of all pregnancies. Previous reports merely demonstrate the existence of choriodecidual infection and/or inflammation in the cause of PPROM (18). As the amniochorionic membranes are connective tissue structures, many studies have focused on the expression of matrix-degrading enzymes in the amniochorionic membranes. In support of this, increases in amniotic fluid matrix metalloproteases (MMPs) (19-21) as well as decreases in tissue inhibitors of MMPs have been reported for women with PPROM (22). Nevertheless, similar findings are observed for normal spontaneous term delivery and infection-induced PL and PPROM. Therefore, degradation of the extracellular matrix seems to be part of the common terminal pathway of human parturition irrespective of the presence or absence of intrauterine infection. Intrauterine infection may accelerate these processes but may probably not be inevitably the initial cause of PL and PPROM.

In the meantime, there is a growing body of evidence that PPROM and uncontrollable PL may be induced by two different pathways. Besides changes in the expression pattern of MMPs and tissue inhibitors of MMPs, the proapoptotic genes p53 and bax were found to be up-regulated in the amniochorionic membranes and the pro-apoptotic cytokine IL-18 was increased in the amniotic fluid of patients with PPROM in comparison with women with PL. Prematurely ruptured membranes also demonstrated fragmented DNA and expression of Fas and caspase-8, all of which were absent in PL membranes $(23,24)$. Previous findings of our own group demonstrated particular importance of tumor necrosis factor- $\alpha$ (TNF- $\alpha$ ) for the detection of PPROM. TNF- $\alpha$ was detectable exclusively in cervicovaginal secretions of patients with term or preterm PPROM but never in patients with intact membranes (25). This cytokine was shown to be the only cytokine studied so far that has the capability of inducing both MMP activity (MMP-9) and apoptosis in the fetal membranes (26,27). Obviously, increased availability of TNF- $\alpha$ and the induction of apoptosis in the amniochorionic membranes are decisive factors in the patho- 
physiology of PPROM but not in the pathophysiology of PL. TNF- $\alpha$ is a main product of activated T lymphocytes, and the lytic activity of cytotoxic $\mathrm{T}$ cells is mediated through the induction of apoptosis by at least two different pathways (secretory perforin/granzyme-based pathway and the Fas/Fasligand based pathway). Therefore, our findings strongly support that increased detection of apoptotic processes in the fetal membranes of patients with PPROM may be caused by an excessive cytotoxic $\mathrm{T}$ cell response of the mother toward the fetal allo-antigens. As the occurrence of PL was not associated with such an excessive maternal cytotoxic $\mathrm{T}$ cell response, our findings also suggest that significant differences in the molecular events that lead to PPROM and PL may exist. Recently, Romero et al. (28) found increased MMP-9 concentrations in the fetal circulation of women with PPROM but not in the fetal circulation of women with PL. In contrast, an increased inflammatory response was detectable in the fetal circulation of women with PL but not in the fetal circulation of women with PPROM. Such findings as well demonstrate considerable differences in the pathophysiology of PL and PPROM.

In addition, PPROM was shown to be associated with the presence of intense maternal intravascular inflammation (29). As yet, such an excessive maternal inflammatory response during pregnancy is reported for the occurrence of preeclampsia (30). Therefore, similar to preeclampsia, the occurrence of PPROM may also be based on dysregulation of the maternal immune system. This assumption may be further confirmed by our findings that PPROM, similar to other pregnancy-specific diseases such as preeclampsia (31) and placental abruption (32), is associated with an increased humoral immune response against the fetus. Probably, most complications in pregnancy are accompanied by different forms of an increased maternal anti-fetal immune response. With regard to pregnancies that are affected by PPROM, it seems that mechanisms that induce tolerance specifically toward the fetal allo-antigens may be disturbed.

\section{REFERENCES}

1. Thellin O 2000 Tolerance to the foeto-placental "graft": ten ways to support a child for nine months. Curr Opin Immunol 12:731-737

2. Sakaguchi S 2000 Regulatory T-cells: key controllers of immunologic self-tolerance. Cell 101:455-458

3. Jonuleit H, Adema G, Schmitt E 2003 Immune regulation by regulatory T-cells: implications for transplantation. Transpl Immunol 11:267-276

4. Aluvihare VU, Kallikourdis M, Betz AG 2004 Regulatory T-cells mediate maternal tolerance to the fetus. Nat Immunol 5:266-271

5. Somerset DA, Zheng Y, Kilby MD, Sansom DM, Drayson MT 2004 Normal human pregnancy is associated with an elevation in the immune suppressive CD25+ CD4+ regulatory T-cell subset. Immunology 112:38-43

6. Puppo F, Contini P, Ghio M, Brenci S, Scudeletti M, Filaci G, Ferrone S, Indiveri F 2000 Soluble human MHC class I molecules induce soluble Fas ligand secretion and trigger apoptosis in activated CD8(+) Fas $(C D 95)(+)$ T lymphocytes. Int Immunol 12:195-203

7. Fournel S, Aguerre-Girr M, Huc X, Lenfant F, Alam A, Toubert A, Bensussan A, Le Bouteiller P 2000 Cutting edge: soluble HLA-G1 triggers CD95/CD95 ligand- mediated apoptosis in activated CD8+ cells by interacting with CD8. J Immunol 164:6100-6104

8. Contini P, Ghio M, Poggi A, Filaci G, Indiveri F, Ferrone S, Puppo F 2003 Soluble HLA-A, -B, -C and -G molecules induce apoptosis in T and NK CD8+ cells and inhibit cytotoxic T cell activity through CD8 ligation. Eur J Immunol 33:125-134

9. Dal Porto J, Johansen TE, Catipovic B, Parfiit DJ, Tuveson D, Gether U, Kozlowski S, Fearon DT, Schneck JP 1993 A soluble divalent class I major histocompatibility complex molecule inhibits alloreactive T-cells at nanomolar concentrations. Proc Nat Acad Sci USA 90:6671-6675

10. Hausmann R, Zavazava N, Steinmann J, Müller-Ruchholtz W 1993 Interaction of papain-digested HLA-class I molecules with human alloreactive cytotoxic T lymphocytes (CTL). Clin Exp Immunol 91:183-188

11. Zavazava N, Kronke M 1996 Soluble HLA class I molecules induce apoptosis in alloreactive cytotoxic T lymphocytes. Nat Med 2:1005-1010

12. Waldmann H, Cobbold S 2001 Regulating the immune response to transplants. A role for CD4+ regulatory cells? Immunity 14:399-406

13. Cobbold SP, Graca L, Lin CY, Adams E, Waldmann H 2003 Regulatory T-cells in the induction and maintenance of peripheral transplantation tolerance. Transpl Int $16: 66-75$

14. Abdelnoor AM 2001 Soluble HLA class I molecules as immune regulators in transplantation. Transplant Proc 33:2850-2851

15. Inostroza J, Ferrada J, Navarrete C, Sorensen RU 1997 Soluble histocompatibility class I antigens and $\beta_{2}$-microglobulin in pregnant females and cord blood samples. Hum Immunol 54:63-68

16. Steinborn A, Rebmann V, Scharf A, Sohn C, Grosse-Wilde H 2003 Placental abruption is associated with decreased maternal plasma levels of soluble HLA-G. J Clin Immunol 23:307-314

17. Yie SM, Li LH, Li YM, Librach C 2004 HLA-G protein concentrations in maternal serum and placental tissues are decreased in preeclampsia. Am J Obstet Gynecol 191:525-529

18. Mercer BM 2003 Preterm premature rupture of the membranes. Obstet Gynecol 101:178-193

19. Athayde N, Edwin SS, Romero R, Gomez R, Maymon E, Pacora P, Menon R 1998 A role of matrix metalloproteinase- 9 in spontaneous rupture of the fetal membranes. Am J Obstet Gynecol 179:1248-1253

20. Maymon E, Romero R, Pacora P, Gervasi MT, Gomez R, Edwin SS, Yoon BH 2000 Evidence of in vivo differential bioavailability of the active forms of matrix metalloproteinases 9 and 2 in parturition, spontaneous rupture of membranes, and intraamniotic infection. Am J Obstet Gynecol 183:887-894

21. Maymon E, Romero R, Pacora P, Gomez R, Athayde N, Edwin S, Yoon BH 2000 Human neutrophil collagenase (matrix metalloproteinase-8) in parturition, premature rupture of the membranes, and intrauterine infection. Am J Obstet Gynecol 183:94-99

22. Vadillo-Ortega F, Hernandez A, Gonzalez-Avila G, Bermejo L, Iwata K, Strauss FJ 3rd 1996 Increased matrix metalloproteinases activity and reduced tissue inhibitor of metalloproteinases-1 levels in amniotic fluids from pregnancies complicated by premature rupture of membranes. Am J Obstet Gynecol 174:1371-1376

23. Fortunato SJ, Menon R, Bryant C, Lombardi SJ 2000 Programmed cell death (apoptosis) as a possible pathway to metalloproteinase activation and fetal membrane degradation in premature rupture of membranes. Am J Obstet Gynecol 182:14681476

24. Fortunato SJ, Menon R 2001 Distinct molecular events suggest different pathways for preterm labor and premature rupture of fetal membranes. Am J Obstet Gynecol 184:1399-1405; discussion 1405-1406

25. Menon R, Lombardi SJ, Fortunato SJ 2002 TNF- $\alpha$ promotes caspase activation and apoptosis in human fetal membranes. J Assist Reprod Genet 19:201-204

26. Fortunato SJ, Menon R, Lombardi SJ 2002 Role of tumor-necrosis-factor- $\alpha$ in the premature rupture of membranes and preterm labor pathways. Am J Obstet Gynecol 187:1159-1162

27. Steinborn A, Kühnert M, Halberstadt E 1996 Immunmodulating cytokines induce term and preterm parturition. J Perinat Med 24:381-390

28. Romero R, Chaiworapongsa T, Espinoza J, Gomez R, Yoon BH, Edwin S, Mazor M, Maymon E, Berry S 2002 Fetal plasma MMP-9 concentrations are elevated in preterm premature rupture of the membranes. Am J Obstet Gynecol 187:1125-1130

29. Gervasi MT, Chaiworapongsa T, Naccasha N, Pacora P, Berman S, Maymon E, Kim JC, Yoshimatsu J, Espinoza J, Romero R 2002 Maternal intravascular inflammation in preterm premature rupture of membranes. J Matern Fetal Neonatal Med 11:171175

30. Redman CW, Sacks GP, Sargent IL 1999 Preeclampsia: an excessive maternal inflammatory response to pregnancy. Am J Obstet Gynecol 180:499-506

31. Steinborn A, Sohn C, Sayehli C, Niederhut A, Schmitt E, Kaufmann M 2001 Preeclampsia, a pregnancy-specific disease, is associated with fetal monocyte activation. Clin Immunol 100:305-313

32. Steinborn A, Seidl C, Sayehli C, Sohn C, Seifried E, Kaufmann M, Schmitt E 2004 Anti-fetal immune response mechanisms may be involved in the pathogenesis of placental abruption. Clin Immunol 110:45-55 